\title{
Antike Orts- und Personennamen
}

Aaron 70, 87-89

Abgar IX. von Edessa 304

Aemilius Macer (Jurist) 133

Ägypten 170, 195, 240, 251-255, 284, 305 , 358

Albinus, Clodius D. 45

Alexamenos 160

Alexander d. Gr. 143

Alexander Severus 173, 251, 263

Alexander (von Jerusalem) 195, 263

Alexandria 7, 193, 195, 197-199, 203, 210, 241-255, 261, 263, 268, 304-307, 351, 354, 358

Ambrosius von Alexandria $\quad 266,273 \mathrm{f}$.

Ambrosius von Mailand $320 \mathrm{f}$.

Amos 216

Antiochia 263, 307

Apollinaris von Hierapolis $52-55,305$

Aquila, Tib. Claudius Subatianus 261

Arabia/Arabien 251, 263f., 307

Archelaus 159

Athen 5, 221, 239, 263f., 300, 302, $306 \mathrm{f}$., 328

Augustus $140,142,300,302$

Bassinus, M. Aurelius 159

Caesar, C. Iulius 143

Capua 152

Caracalla 74, 105f., 154, 158, 189, 251, 253

Carpus, M. Aurelius 159

Cäsarea (Kappadokien) 195, 264

Cäsarea (Maritima) 94, 157, 258, 263-265, 306, 319 f., 327, 332, 336, 358

Cassius, C. Avidius 52 f., 56

Celerinus 78

Claudius Iulianus 261

Commodus 50, 53, 153, 158f., 285

Corbulo, Cn. Domitius 251

Cornelius von Rom 109

Cornelius (Zenturio) 94, 132, $359 \mathrm{f}$.

Cyrenaica 253

Daniel $73,75 \mathrm{f}$.

David 150, 216

Decius 48, 274f., 305, 339

Demetrius von Alexandria $\quad 260,263,351$
Didymus 306

Dionysius von Alexandria 305

Dometius 306

Domitian 49, 139

Egnatius 78

Elagabal 173

Ephesus 264, 307

Firmilian von Cäsarea (Kappadokien) 264

Gaianus 306, 359

Germanien/Germanen 47, 50-52, 267

Geta 105f., 154

Griechenland 140, 263, 304

Hadrianswall 152

Hauptmann von Kapernaum 91, 94, 131

Hesekiel 216

Hierapolis $\quad 52,54,305$

Hosea 216

Isai/lesse 150

Jeremia 216

Jerusalem 195, 263, 302

Jesaja 216

Jesus (von Nazareth) / Christus 10, 69 f., 72, $75 \mathrm{f} ., 78,83-85,90-92,94,96,102 \mathrm{f}$., 113, 115 f., $119-121,127-130,132,137$, 140,150 f., 162, 165, 168, 204, 209, $211-$ 217, 224, 226, 228, 230-232, 24, 245 , 269, 273, 279, 285, 293, 300 f., 317, 319, $323,328-334,338-348,355$

Johannes d. Täufer $70,88,91,116,131,212$, $215-217,220,246,322-324$

Joseph 73,75

Josua/Jesus Nave 70, 88f., 327-330, 332

Judäa 140

Julia Maesa 173

Julia Mamea 263

Kapernaum 91, 94, 132

Karthago 7, 36 f., 39, 42, 45, 64, 72, 76-78, $80-82,107$ f., 109, 111, 137, 158, 167, 187, 189,192 f., 354

Kleinasien 52, 54, 253, $304 \mathrm{f}$. 
Laetus, Q. Maecius 261

Lambaesis $81,107,158$

Laurentinus 78

Leonides 259

Lucius Verus 251

Malchus $102,342 \mathrm{f}$.

Marathon 239

Marcellus 98

Marcus Aurelius 47, 50-54, 72, 159, 267, 285

Marinus 156f., 158, 160, 306

Marius, C. 143

Maximianus, M. Valerius 158

Maximilianus 84

Megiddo $306 \mathrm{f}$.

Melitene 53, 305, 358

Menander (Jurist) 134

Miltiades 238

Mose $70,87-89,214,216,239 f ., 271,284$, $301,329,343$

Nero 49, 143

Niger, C. Pescennius 45

Nikopolis 252, 254

Palästina 263, 304

Paternus (Jurist) 169

Paulus 90, 124, 128, 165, 207, 209f., 214, $216,225,318,324,343$

Paulus (Jurist) 98

Paulus von Concordia
Petrus $70 \mathrm{f} ., 88,90-92,94-96,116,124$, 132, 213, 334, 340, $342 \mathrm{f}$.

Phokion 221

Phönizien 253

Pompeius, Cn. 143

Priscianus, A. Caecidius 159

Prosenes, M. Aurelius 307

Rom 7, 105-110, 158-160, 172-174, $192 \mathrm{f}$, 263f., 268, 274, 296, 302, 305, 307

römisches Nordafrika/Africa (proconsularis)/ Numidia $36,39-43,45,58 f ., 81,107$, 109, 158, 189, 192f., 253, 305

Salomo 216

Septimius Severus $\quad 45,74,105,109,153 \mathrm{f}$., 158 f., 178, 188 f., 192f., 249, 251, 261

Severus, Cn. Pinarius 296

Syrien 253, 293, 304

Theoctistus von Cäsarea (Maritima) 263

Thrasybulos 239

Tiberius $\quad 40-43$

Trajan 48, 139, 145, 251, 254

Ulpian (Jurist) $\quad 75,122,133$

Valerian 109, 305

Vespasian 139

Vindovala 152 